\title{
Modeling and Performance Analysis of an Adaptive PID Speed Controller for the BLDC Motor
}

\author{
Md Mahmud ${ }^{1}$, S. M. A. Motakabber²*, A. H. M. Zahirul Alam³ ${ }^{2}$ Anis Nurashikin Nordin ${ }^{4}$, A. K.M. Ahasan Habib ${ }^{5}$ \\ Department of Electrical and Computer Engineering \\ International Islamic University Malaysia \\ Kuala Lumpur, Malaysia
}

\begin{abstract}
Brushless Direct Current (BLDC) motor is the most popular useable motor for automation and industry. For good performance of the BLDC motor hunger driving circuit but the driving circuit is costly, complex control mechanism, various parameter dependency and low torque. The Proportional Integral (PI), Proportional Integral Derivative (PID), fuzzy logic, adaptive, Quantity Feedback Theory (QFT), Pulse Width Modulation (PWM) controller are the common types of control method existing for the BLDC motor. This research explores some well-working experiments and identified the PID controller as far more applicable controller. For well efficacious and useful in getting satisfied control performance if the adaptability is implemented. This research proposed a combined method using PID and PID auto tuner, having the ability to improve the system adaptability, given the method named as adaptive PID controller. To verify the performance, MATLAB simulation platform was used, and a benchmark system was developed based on the actual BLDC motor parameters, auxiliary systems, and mathematically solved parameters. All work has done by using MATLAB/ Simulink.
\end{abstract}

Keywords-QFT; PWM; BLDC motor; PID controller; adaptive; adaptive PID controller; APIDC

\section{INTRODUCTION}

Brushless DC motor is getting more popular and operational motor than the other DC motor. It requires less maintenance and can have a life span as it has no wearable brush and has level speed-torque properties, high productivity. In driving, from an assortment of motors, BLDC motors have been generally utilized in automated, restorative hardware, vehicles, aviation, hard circle drive, as the benefits of BLDC are extraordinary execution, advance and lower assurance in power factor. The BLDC motors are increasingly costly, and its controller design is more complex [1]. Also, need to focus on BLDC motor safety and inverter because it delivers a high risk of security issues, demagnetization problem and inverter disappointment. Controlling the motor speed of the BLDC requires the controller circuit framework for good productivity. Numerous kinds of speed control frameworks have been produced for controllers, yet speed controllers must be refreshed with age. Right now, there are two circles for speed control of the BLDC motor. For instance, the electronic force motor speed controller for the inward circle tuning and an outside circle for inverter permits the very voltage of the DC vehicle [2]. To control this framework, the DC supply required relies upon the motor RPM and its capacities. The sensor is the most significant piece of the controller for controlling the motor speed. The sensor can stream directions. The inverter used to change over DC voltage to AC voltage likewise has a DC voltage converter to change over DC to this framework. In any case, when utilizing a brush dc motor, mechanical rubbing, and electrical erosion mess some up which urge the inclination to utilize brushless dc (BLDC) motor. These days, BLDC motors are generally utilized in electronic vehicles, because the nonattendance of a brush/transport gathering decreases hearing sharpness and improves productivity and torque [3]. A wellknown magnet brushless DC motor (PMBDCM) is mainstream and utilized BLDC motor utilized as a variable speed drive framework for mechanical, car, aviation, and computerization applications. The rotor is made electronically rather than a stator and a permanent magnet and computation brushless. There are two types of brushless motor: Namely, brushless AC motor and brushless DC motor. The brushless AC motor (perpetual magnet simultaneous motor) and the brushless DC motor rely upon the current frequency. The brushless AC motor is consumed by the sinusoidal current while the brushless DC motor is consumed by the rectangular stream [4]. Studies have been directed to quantify force swell in brushless DC motor [5]. It is unordinary for papers to depict the estimation of electromagnetic force delivered by a brushless DC motor utilizing current stage information. Motor force can be estimated straightforwardly by a force sensor which can be costly and can now and again be overwhelming when applied to explicit applications. Assessments of electromagnetic force with quantifiable limits, for example, back EMF, rotor speed and stage current are deeply alluring [6]. The electromagnetic force of a brushless DC motor can be assessed by estimating the stage movements by asserted that in any event two current sensors were expected to assess the electromagnetic force. Initially, these procedures were utilized legitimately as BLDC motor controllers. Immediately, the FLC was applied to control the speed of the BLDC motor [7]. It is described by its capacity to manage inadequately characterized numerical models. The FLC rules required to make control directions rely to a great extent upon the human experience. Notwithstanding, FLCs require additional time than regular control strategies, for example, PI and PID to determine complex fuzzification and cleansing procedures [8]. In this research applied two types controller one is PID controller another one is PID-Auto tuner both are combined, and it called adaptive PID controller. This study aims to develop a controller drive to control BLDC motor speed and torque and compare controller output result with benchmark controller. This works done by using MATLAB/ Simulink.

*Corresponding Author 
This article is organized into five distinct sections. After the abstract, the article starts with the introduction as Section I discusses BLDC motor and its control system. Section II introduces and discusses the basic models of a BLDC motor and speed control systems. In Section III, the method and the MATLAB simulation model are discussed in detail. Section IV is illustrated by graphical results obtained from MATLAB models of Section III. Finally, this research article is concluded by a conclusion, Section number V.

\section{BASIC MODEL AND SPEEd CONTROL OF BLDC MOTOR}

Fig. 1 shows the basic model of the Adaptive PID controller. To develop motor controlling controller many scholars, follow the different method and technic. In this research also apply another technic to increase the motor speed. For better output efficiency of the BLDC, motor speed control is very impotent in this situation. So, solved this problem and get better efficiency proposed this basic model. The motherboard has a three-triode power converter, as it conveys six force transistors all the while on a BLDC motor. The MOSFET transistors have a rotor position, which will be characterized as the exchanging succession. The starter is the objective of each of the three gadget gadgets. The Hall sensor is the data that the decoder square creates in the EMF of the reference current sign vector. Enacting the switch side of the invert flows for the contrary side of the moving motor.

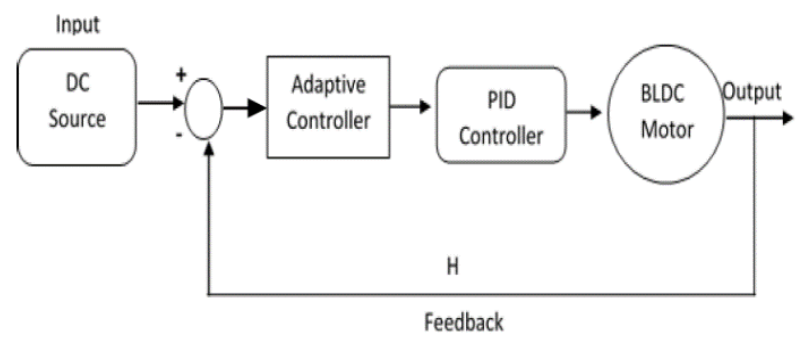

Fig. 1. Basic Block Diagram of an Adaptive PID Controller.

\section{CONTROLLER AND RESEARCH METHOD}

The proposed controller was simulated by the MATLAB simulation process, but the controller needs to develop mathematical equations and monitor the performance of simulation-based.

\section{A. Proposed Adaptive-PID Controller}

The Adaptive PID auto-tuner is the combined controller, that working in a series of PID and PID auto-tuner controller. This combination of the combined controller has the adaptability over any circumstances, as like the increasing number of input decision change. The Adaptive PID auto-tuner block is containing both controllers in series. In Fig. 2, the Adaptive PID auto-tuner controller is shown with the motor transfer function and inside the Adaptive PID auto-tuner controller block, where both controllers are connected in series.

\section{B. FPA based BLDC Speed Controller, Benchmark Paper}

One of the researches has done on Flower Pollination Algorithm (FPA) for speed control of BLDC motor with optimal PID tuning [9]. In that work, the optimization-based approach is applied for tuning of PID speed controller by considering an integral square error as the objective function.
This model also followed the cascade mode, the speed control loop and voltage control loop. Both controllers followed the PID basic controller inside where FPA method algorithm was developed. Though the method looks good, on the benchmark platform it was giving overshoot which is higher than a normal phenomenon. Fig. 3 shows the FPA speed controller.

\section{Equations}

The model of the armature contorting for the BLDC motor is communicated as pursues:

$v_{a}=R i_{a}+L \frac{d i_{a}}{d t}+e_{a}$

$v_{b}=R i_{b}+L \frac{d i_{b}}{d t}+e_{b}$

$v_{c}=R i_{c}+L \frac{d i_{c}}{d t}+e_{c}$

where $L$ is armature self-inductance $[H], R$ - armature resistance $(\Omega), v_{a}, v_{b}, v_{c}$ - terminal phase voltage $(V), i_{a}, i_{b}, i_{c}$ - motor input current (A), and $\mathrm{e}_{\mathrm{a}}, \mathrm{e}_{\mathrm{b}}, \mathrm{e}_{\mathrm{c}}$ - motor back-emf (V). The equivalent circuit for one phase is represented in Fig. 4. In the 3-stage BLDC motor, the back-emf is identified with an element of rotor position and the back-emf of each stage has 120 degrees stage point distinction so the condition of each stage ought to be as per the following:

$\mathrm{e}_{\mathrm{a}}=\operatorname{Kef}(\theta \mathrm{e}) \omega$
$\mathrm{e}_{\mathrm{b}}=\operatorname{Kef}(\theta \mathrm{e}-120) \omega$
$\mathrm{e}_{\mathrm{c}}=\operatorname{Kef}(\theta \mathrm{e}+120) \omega$

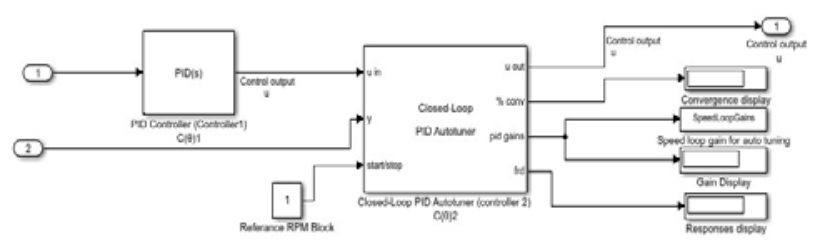

(a)

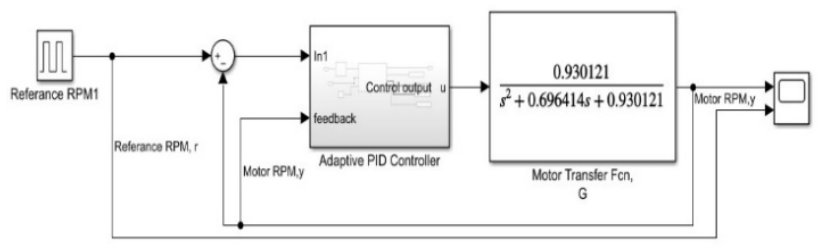

(b)

Fig. 2. MATLAB Model (a) Adaptive PID Auto-Tuner Controller in CloseLoop System and (b) Inside Adaptive PID Auto-Tuner Block.

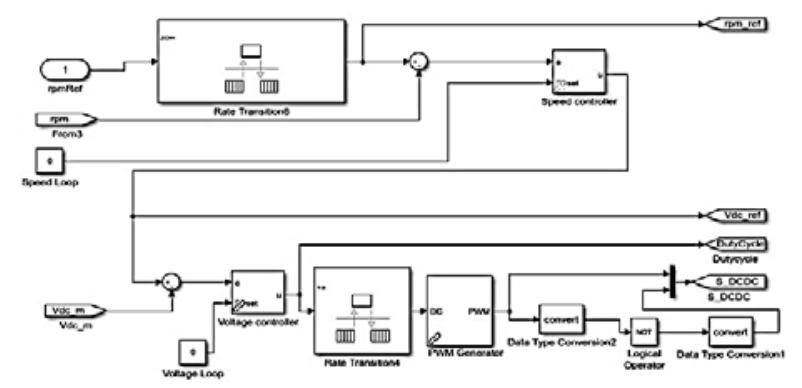

Fig. 3. The FPA based Controller for BLDC. 




Fig. 4. Equivalent Circuit of the BLDC Motor for One Stage.

where $K_{e}$ is back-emf constant (V/m - RPM)1, $\theta$ e electrical rotor angle ( $\mathrm{e}$ - degrees), $\omega$ - rotor speed ( $\mathrm{m}-\mathrm{RPM}$ ).

The electrical rotor point is equivalent to the mechanical rotor edge duplicated by the number of post sets $\mathrm{p}$ :

$\theta \mathrm{e}=\mathrm{p} \theta \mathrm{m}$

where $\theta_{\mathrm{m}}$ is the mechanical rotor edge ( $\mathrm{m}$ - degrees).

The absolute torque yield can be spoken to as a summation of that of each stage. Next condition speaks to the all-out torque yield or electromagnetic torque:

$T_{e}=\frac{e_{a} i_{a}+e_{b} e_{b}+e_{c} e_{c}}{\omega}=K_{T} \frac{3}{2} i_{q}$

where $T_{e}$ is total torque output $\left(\mathrm{N}_{\mathrm{m}}\right), K_{T}$ - motor constant $(\mathrm{Nm} / \mathrm{A}), i_{q}$ - quadrature current $(\mathrm{A})$.

\section{Simulation Model for the Proposed Controller}

Fig. 5 shows the overall simulation model of an adaptive PID controller with connected 3-phase BLDC motor with Load. There are many parameters used to design this controller also used mathematical equation in this controller. At first, fixed reference R.P.M than reference rpm and load connected with the controller. There are two types of controller used one is PID and another one is the adaptive controller. After completing all mechanism than signal comes to MOSFET drive and then comes buck converter.

A buck converter (step-down converter) is a DC-to-DC power converter that brings down the voltage (while streaming current) from its information (supply) to yield (load). Its also connected with DC voltage source, motor and output connected with 3-phase inverter and voltage sensor. An inverter connected with IGBT drive and current sensor. Current sensor connected with BLDC motor.

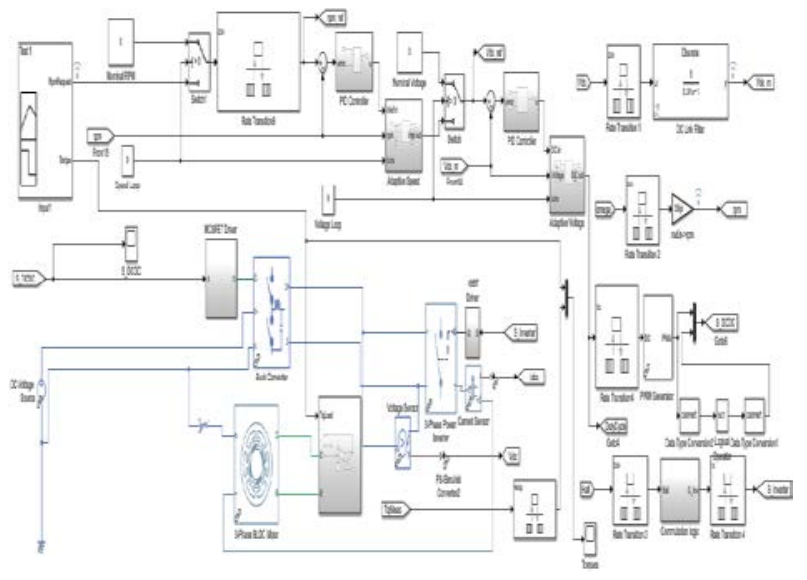

Fig. 5. Proposed Simulation mode of Adaptive PID Controller.

\section{RESUlt AND Discussion}

\section{A. Controller Output Applying $24 \mathrm{~V}$, Torque $T_{e}-10 \mathrm{~N}-\mathrm{m}$ for 1000 RPM}

Fig. 6 and Table I shows the adaptive PID controller output. This output with torque load $T_{e}, 10 \mathrm{~N}$-m and its supply voltage is 24 DC volt. The output of the controller had no overshoot and undershoot is $45 \%$ (24V/unit), settling time 1seconds ( 0.1 seconds/unit) and had no steady-state error after 3secs this is not at the stable point. The performance indicates that the adaptive PID controller has satisfactory controllability than the existing other controller but still it can improve. So, the results of the proposed adaptive PID controller simulation model for the BLDC motor speed control.

\section{B. Controller Output Applying 48V, Torque $T_{e}-10 \mathrm{~N}-\mathrm{m}$ for 1000 RPM}

Fig. 7 shows the adaptive PID controller output. This output with torque load $T_{e} 10 \mathrm{~N}-\mathrm{m}$ and its supply voltage is 48 DC volt. The output of the controller had an overshoot of $0.497 \%$ and undershoot is $1.833 \%$ ( $48 \mathrm{~V} /$ unit), settling time 0.35 seconds (0.1seconds/unit) and had no steady-state error. The performance indicates that the adaptive PID controller has very good controllability than the existing other controllers. So, the results of the proposed adaptive PID controller simulation model for the BLDC motor speed control. This research conducts the mathematical modelling for 1000 RPM for that motor. Here the simulation results are shown in Fig. 7 and the are shown in Table II.

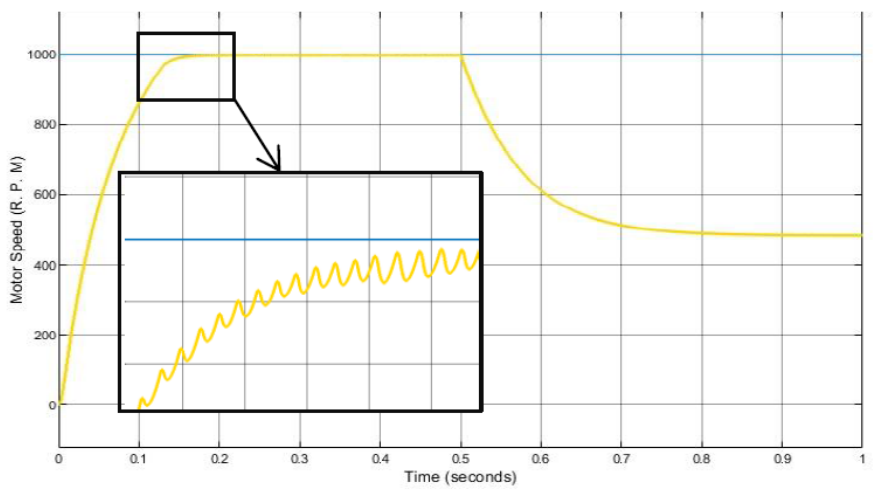

Fig. 6. The Output of the Adaptive PID Controller Applying 24V.

TABLE I. SimUlated MEASUREMENTS FOR $24 \mathrm{~V}$

\begin{tabular}{|l|l|}
\hline Measurements & Time \\
\hline Rise time (With load) & $0.034319 \mathrm{~s}$ \\
\hline Max / Min high (Without load) & 999.99 RPM / 997.3 RPM \\
\hline Max / Min high (With load) & 483.5 RPM / 482.7 RPM \\
\hline Without load RMS & 998.5 RPM \\
\hline With load RMS & $482.4 \mathrm{RPM}$ \\
\hline Without load overshoot & No \\
\hline With load $E_{\text {ss }}$ (Steady State Error) & $51.76 \%$ \\
\hline
\end{tabular}




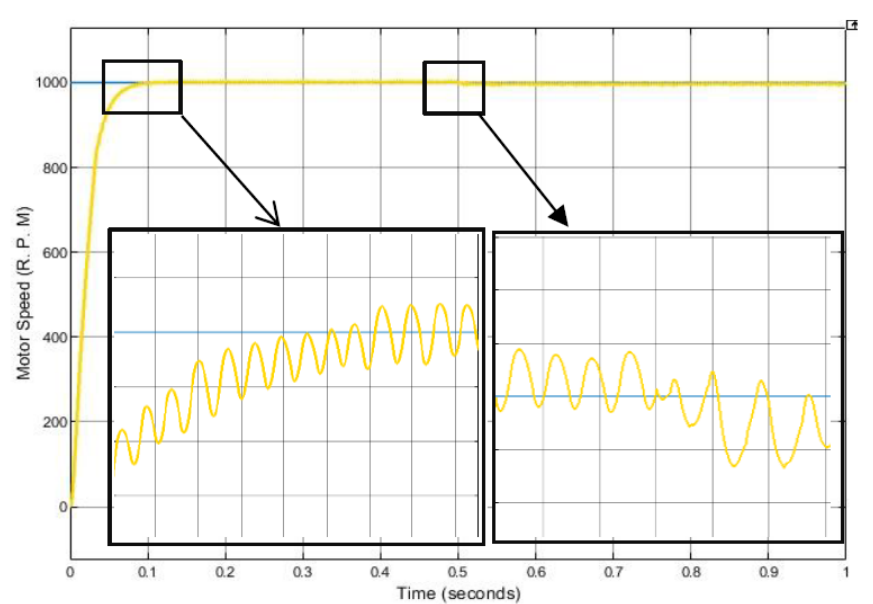

Fig. 7. Output of the Adaptive PID Controller Applying 48V.

TABLE II. SIMULATED MEASUREMENTS FOR 1000 RPM

\begin{tabular}{|l|l|}
\hline Measurements & Time \\
\hline Rising time & $31.386 \mathrm{~ms}$ \\
\hline Max / Min high & $1001 \mathrm{RPM} / 993.939 \mathrm{RPM}$ \\
\hline With load maximum high & $999.3 \mathrm{RPM}$ \\
\hline Overshoot & $0.452 \%$ \\
\hline With load overshoot & $0.197 \%$ \\
\hline With load undershoot & $1.833 \%$ \\
\hline
\end{tabular}

\section{FPA Speed Control System, Applying 48V, Torque Te} $10 N-m$ for $1000 R P M$

The Flower Pollination Algorithm (FPA) also one of the popular controllers already describes in Fig. 3. This controller is one of the smooth performance controllers, can be used for any slow process system. Fig. 8 shows the performance of the FPA controller performance. The controller gave 1098 RPM having unexcitable overshoot of $9.34 \%$. While applied load, it again gave $3.646 \%$ undershoot, but with time smoothly came back to the required line. When, the sudden load applied to the system, immediately a high undershoot and overshoot formed due to its slow response. This response is not only for this system, but most of the research also found the same issue. The controller is perfect for a system, where slow response and steady performance is required. The performance specifications are given in Table III for better understanding.

TABLE III. FPA BASED SPEED CONTROLLER PERFORMANCE ON THE SIMULATION PLATFORM

\begin{tabular}{|l|l|}
\hline Measurements & Time \\
\hline Rise time (With load) & $0.03415 s$ \\
\hline Max / Min high (Without load) & 1098 RPM / 998.7 RPM \\
\hline Max / Min high (With load) & 1038 RPM / 994.5 RPM \\
\hline Without load RMS & 1003 RPM \\
\hline With load RMS & 1001 RPM \\
\hline Without load overshoot & $9.34 \%$ \\
\hline With load undershoot & $3.646 \%$ \\
\hline
\end{tabular}

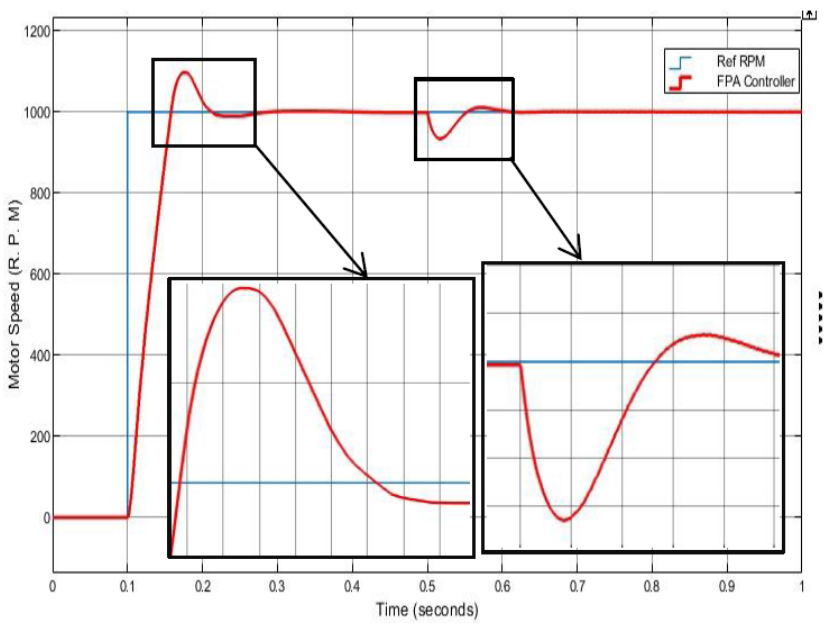

Fig. 8. FPA Speed Controller Output Applying 48V.

\section{Compare with Benchmark Controller}

Fig. 9 shows the adaptive PID controller output and FPA speed controller output. This output with load condition and its supply voltage is 48 volts. Reference rpm is 1000 after running the output of the adaptive PID controller had an overshoot of $0.197 \%$ and undershoot is $1.833 \%$ ( $48 \mathrm{~V} /$ unit), settling time 0.05 seconds (seconds/unit) and had no steady-state error. On the other hand, the FPA speed controller had an overshoot of $9.34 \%$ and undershoot is $3.646 \%$ ( $48 \mathrm{~V} / \mathrm{unit}$ ), settling time is unknown and had a steady-state error. The performance indicates that the adaptive PID controller has good controllability than the existing others So, The results of the proposed adaptive PID controller simulation model for the BLDC motor speed control. The Pre-shoot, overshoot and undershoot can be reduced mainly by using a high-frequency noise and filter [10].

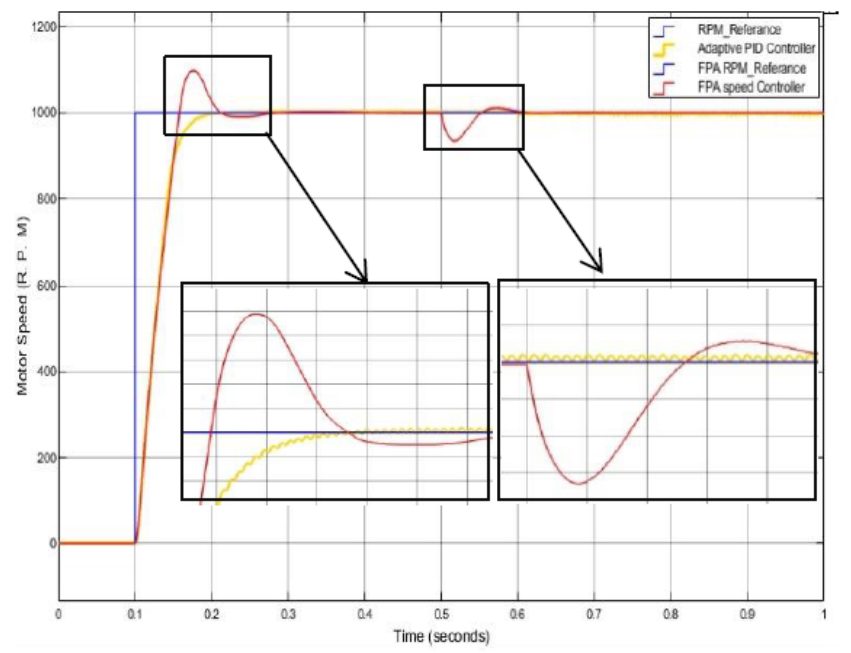

Fig. 9. Adaptive PID and PFA Speed Controller, Applying 48V, Te-10 N-m.

\section{CONCLUSION}

This controller design for three-phase BLDC motor for its speed control. An adaptive PID controller technology has more advanced to control BLDC motor. As a result, an adaptive PID controller gives excellent Simulation results than the other 
controller system. However, it is worth noticing that when the motor functions at up and down speeds, for it to be well responsive, the motor speed must be continuous when the load will change. This research aims almost completed but still need to remove it noise for smooth speed control. The aims of the study will be developed a Prototype control drive using this adaptive PID controller to control BLDC motor speed. This simulation work helps to developed BLDC motor speed and efficiency.

\section{FUTURE WORK}

This research primarily has been developed a basic foundation of the proposed adaptive PID speed controller for the BLDC motor, and verified the design by simulation successfully. Further experimental tests can be conducted in the future for a detailed evaluation of this research and to further strengthen the claim of its achievement.

\section{ACKNOWLEDGMENT}

This research has been supported by the Malaysian Ministry of Education through the Fundamental Research Grant Scheme under the project ID: FRGS19-054-0662.

\section{REFERENCES}

[1] P. Yedamale, "Brushless DC (BLDC) motor fundamentals”, Microchip Technology Inc, 20, pp.3-15, 2003.

[2] H. B. Wang, H. P. Liu, "A novel sensorless control method for brushless DC motor,” IET Electr. Power Appl, Vol. 3(3), pp. 240-246, May 2009.
[3] M. V. Rajkumar, G. Ranjhitha, M. Pradeep and M. F. Kumar, "Fuzzybased Speed Control of Brushless DC Motor feed electric vehicle”, IJISSET, vol. 3(3), 2017.

[4] N. Hashemnia and B. Asaei, "Comparative study of using different electric motors in the electric vehicles," 2008 18th International Conference on Electrical Machines, Vilamoura, 2008, pp. 1-5, doi: 10.1109/ICELMACH.2008.4800157.

[5] D. C. Hanselman, "Minimum torque ripple, maximum efficiency excitation of brushless permanent magnet motors," in IEEE Transactions on Industrial Electronics, vol. 41, no. 3, pp. 292-300, June 1994, doi: 10.1109/41.293899.

[6] M. Mahmud, S. M. A. Motakabber, A. H. M. Z. Alam, A. N. Nordin, "Adaptive PID controller using for speed control of the BLDC motor", 2020 IEEE International Conference on Semiconductor Electronics (ICSE),2020.

[7] L. Sun, H. Gao, Q. Song, J. Nei, "Measurement of torque ripple in PM brushless motors," Conference Record of the 2002 IEEE Industry Applications Conference. 37th IAS Annual Meeting (Cat. No.02CH37344), Pittsburgh, PA, USA, vol. 4, pp. 2567-2571, 2002. doi: 10.1109/IAS.2002.1042808.

[8] J. Shen, Z. Zhu, D. Howe, and J. Buckley, "Fuzzy logic speed control and current-harmonic reduction in permanent magnet brushless ac drives," IEE Proceedings-Electric Power Applications, vol. 152(3), pp. 437-446, 2005.

[9] D. Potnuru, D., "Experimental implementation of Flower Pollination Algorithm for speed controller of a BLDC motor", Ain Shams Engineering Journal, Vol. 10(2), pp. 287-295, 2019.

[10] M. Mahmud, S. M. A. Motakabber, A. H. M. Z. Alam, A. N. Nordin, "Control BLDC Motor Speed using PID Controller", International Journal of Advanced Computer Science and Applications(IJACSA), Vol.11(3), pp. 477-481, 2020. 